Draft of article submitted to Anthropology and Humanism (2019). For the publisher's version please search for: 10.1111/anhu.12234

\title{
Poetry First Prize (tie)
}

\section{IZA KAVEDŽIJA}

Faculty of Sociology, Philosophy, and Anthropology

University of Exeter

I.Kavedzija@exeter.ac.uk

\section{worlds apart, or two fieldsites}

A circle of crimson/ behind the bleak beam of monorail/ plump persimmon

[and no response for six days]

Dark shadows/worry or/fatigue setting in

[another three days pass ... ]

antenna eager / searching the fast cooling sky / where message awaits?

Numbers the rain drums on my sill:

Fifth day of rain now./25th day without my T./

Fourth cup of coffee./ Countless sent kisses

Boiled three toed sloth. Serves 10. Difficulty: easy. Take 1 sloth, scorch and remove hair, butcher. Boil in pot. Add salt, whole green bananas. When tender, remove pieces and serve with side of banana. Delicious as breakfast or any time of day.

Men in suits/ their transparent umbrellas reveal/ impenetrable faces

Rain turns earth to mud / spiders, gossip, boredom, fish / beer still falls like rain

Grey buildings and clouds/ Parted / After the storm/

A girl and her father blowing bubbles / Silent smiles of the passer by

These days/it gets late/early

its late early here / but it's early early too / who will sleep till nine?

Like honey / Sunday entraps me/ all stands still

all time like honey / here there is only sunday / life of mixed blessings 
Draft of article submitted to Anthropology and Humanism (2019). For the publisher's version please search for: 10.1111/anhu.12234

\section{(no longer mine) view of Utsubo park}

Handing back my keys

I catch a glimpse through the window

Sun and rain

Ethnographic Statement I did my fieldwork in the Japanese city of Osaka, where the intense sociality of fieldwork contrasted strongly with quiet anonymity of a large city on the days I had to spend writing and applying for jobs. Poems grew in these cracks of loneliness. The first poem is an exchange of short messages with my husband Harry Walker, while we were both in the field in 2013. The communications, sent as 160 character texts over the satellite phone, travelled between Osaka and a small community on the river Chambira, a tributary of the Amazon in Peru. The messages arrived every two or three days. Charging the satellite phone in the village was impossible at the time, so preserving the battery restricted Harry to intermittent use and me to a state of worry and expectation. The brevity of the messages made everyday communications feel both trivial and awkward. The incongruity of our fieldwork experiences amused us. The second poem was written a day before my departure from the field. The real estate agent arrived at my apartment, I greeted him with a bow at the threshold of the genkan entryway, where he slipped his shoes off. After a quick check of the property I slipped my shoes on and with a mirroring bow, receded out of the flat. 